\title{
Measuring and Analyzing the Common and Idiosyncratic Cycles: An Application for Turkish Manufacturing Industry
}

\author{
Emel Siklar \\ Anadolu University, FEAS, Department of Numerical Methods \\ Yunus Emre Campus, 26470 Eskisehir, Turkey \\ E-mail: esiklar@anadolu.edu.tr \\ Ilyas Siklar (Corresponding author) \\ Anadolu University, FEAS, Department of Economics \\ Yunus Emre Campus, 26470 Eskisehir, Turkey \\ E-mail: isiklar@anadolu.edu.tr
}

Received: April 19, 2021 Accepted: May 24, 2021 Published: June 1, 2021

doi:10.5296/ber.v11i2.18542ＵRL: https://doi.org/10.5296/ber.v11i2.18542

\begin{abstract}
This study uses the Butterworth filter to decompose cyclical signals at low and high frequencies in the production data of the manufacturing industry and its sub-sectors. At low frequencies, the production trend exhibits considerable differences among industrial activities while most of the sub-sectors are more sensitive to common cycle than their own dynamics at high frequencies. Moreover, it is predicted that changes in the manufacture of basic metals sub-sector production can be used as a leading indicator for the expansion and contraction periods of the common cycle estimated for the manufacturing industry.
\end{abstract}

Keywords: Unobservable components, Butterworth filter, Idiosyncratic cycle

\section{Introduction}

Factors affecting production and profits in a firm are studied extensively in economic theory. Although it is necessary to have effective management in liquidity, profitability, and indebtedness issues in the production process, the macroeconomic environment and economic cycles in general gain importance when examining long-term production. The 
definition of the economic cycle made by Burns \& Mitchel (1946) expresses a series of fluctuations that consist of the expansion and contraction of productive activities. The average duration of these fluctuations, in the context of the time elapsed between the two expansion periods, ranges from 1.5 years to 8 years. If these fluctuations are experienced in a large number of sectors, they form the economic (common) cycle, and if they are specific to production activity, they form the idiosyncratic cycle.

Cycles (common or idiosyncratic) and trend constitute unobservable components of production series. Different techniques have been developed in the literature to estimate these components and to convert them into numerical form. The first of these techniques is the one proposed by Burns \& Mitchel (1946) to measure production cycles in England, Germany, and the USA. Although this study has been criticized extensively due to the subjective criteria it uses to determine trend changes in the relevant series, its results coincide with the results obtained from new and more complex methods used recently for production and investment data in the USA.

After this first method, alternative methods have been developed that can be divided into three groups according to their characteristics. In the first group, some studies aim to determine the duration of the cycle and turning points in production through indicators or econometric time series models (Stock \& Watson, 1998 and Emerson \& Hendry, 1998). The other two groups are based on the separation of unobservable components from the series. Accordingly, the second group includes univariate filters (Hodrick \& Prescott, 1980 and Baxter \& King, 1998), while the third group includes band-pass filters (Christiano \& Fitzgerald, 2003) and structural models using generalized band-pass filters (Harvey \& Timbur, 2003 and Pelagatti, 2005).

Empirical evidence obtained for Turkey uses the methods in the first two groups. In the first group of these studies, it is suggested to create reference indicators depending on a series of variables related to production activities (Alper, 1998; Alper, 2002; Atabek et al., 2005; Alp et al., 2012 and Asik, 2020). The second group of studies aims to calculate the cyclical components of the series to obtain the properties and chronology of the cycles (Senyuz, 2002; Berument et al., 2005; Ozkan \& Erden, 2007; Korap, 2007; Pagan, 2010; Akkoyun et al., 2011 and Binici et al. al., 2016).

This study aims to analyze production activities in Turkey through structural models based on generalized band-pass filters. Because of its importance in the total output of the economy according to production data compiled by the Turkish Statistical Institute (TUIK), the current study focuses on the industrial sector. In the 1998-2020 period, the average share of the services sector in GDP was $22.9 \%$, while the share of the industrial sector was in second place with a share of $19.2 \%$. On the other hand, the most important sub-sector in terms of its contribution to GDP in the industrial sector is the manufacturing industry with approximately $82 \%$. In accordance with this data, approximately $25 \%$ of the employment in the cities was realized by the industrial sector in the same period.

Examination of unobservable components of production series will provide useful information for regulating sectoral policies. Thanks to the information to be obtained, it will 
be possible to prioritize the necessary measures to support production while at the bottom of the cycle. In this study, we aim to measure the said trend and cycle components for total manufacturing industry production and its basic sub-sectors using TUIK's monthly industrial production index data. Thus, the main purpose of this study is to examine whether the production fluctuations observed in the sub-sectors exhibit the same dynamics as the main sector.

Decomposition of industrial production series cannot be accomplished using univariate filters such as the Hodrick - Prescott filter. This is because the results produced by these methods do not change when the order of the decomposition of the relevant components is changed and, therefore, they can produce false cycles (Harvey \& Jaeger, 1993; Gomez, 2001 and Pelagatti, 2005). To avoid these drawbacks, we will prefer to use Butterworth (1930) filter, which is one of the generalized band-pass filters and extracts both components at the same time. Our results indicate that the cycles are irregular and have a long period of 4 years for the manufacturing industry. It appears that there is a strong synchronization between idiosyncratic cycles (excluding manufacture of textiles and manufacture of coke, refined petroleum products) and total manufacturing industry cycles, as the economic cycle in the total manufacturing industry is strongly spreading to sub-sectors. This shows us that the external shocks that will be experienced in the sector will affect most of the production activities.

In addition to this introduction, the study is organized into four sections. The first section describes the data used in terms of the main manufacturing industry and its sub-sectors. The second chapter explains the Butterworth filter and its advantages over traditional methods. While the estimation results are presented in the third part, the fourth part concludes the study.

\section{Data}

The estimation of the common cycle in the manufacturing industry and the idiosyncratic cycles for activities in the sub-sectors will be realized using monthly production indices compiled by TUIK for the period January 1996 - December 2020. Since the monthly production series is a stock variable, it is converted into quarterly by taking the average of the months corresponding to the relevant quarter. Thus, the current study uses the quarterly data for the 1996:1 - 2020:4 period covering 100 observations.

The manufacturing industry production index is a basic indicator that expresses the industrial production dynamics in the economy. Although there were some methodological changes (such as NACE Rev2) in measuring values in the industrial sector during the analyzing period, most of these changes are related to sub-sector detailing. There is no change at a level that will affect the results in the context of the main sub-sectors of the manufacturing industry. On the other hand, there are base year changes made by TUIK during the period considered. Current industrial production index $(2015=100$ based index $)$ starts from 2005: January. For the rest of the period covered (1996: January - 2004: December) there is another production index that uses 1997 as the base year. As can be seen in Appendix 1, the trends of the two series largely overlap. For this reason, the current production index series is extended 


\section{Macrothink

backward by using the change rate of the $1997=100$ index and the series covering the entire period studied is obtained.

The sub-sectors discussed in this study are the 10 sub-sectors that contribute the most to manufacturing industry production. As of 2019, the aforementioned contributions can be traced in Table 1 . The sub-sectors listed in the table represent approximately $84 \%$ of the manufacturing industry production. Some sub-sectors are not included in the table either because the value of their production is very low (like the manufacture of basic pharmaceutical products and pharmaceutical preparations) or because the production data is not disclosed by TUIK (like the manufacture of computer, electronic and optical products) (Note 1). The manufacture of food products and basic metals constitute the two most important manufacturing industry sub-sectors with a total share of approximately $26 \%$ among the manufacturing industry sub-sectors in the table. The top 10 sectors, which have the highest share in terms of their contributions, will be discussed within the scope of this study. The said top 10 sub-sectors represent approximately $74 \%$ of the total manufacturing industry production.

\section{Estimation Methodology}

The empirical literature has faced difficulties from the outset in identifying appropriate methods for decomposing a time series into its components. In this sense, traditional filters such as the Hodrick - Prescott filter have been heavily criticized for producing erroneous cycles when the order of extracting the components is changed (Harvey \& Jaeger, 1993; Gomez, 2001 and Pelagatti, 2005). In terms of frequencies, the Hodrick - Prescott filter is a type of low pass filter since the purpose of this technique is to extract the long-term trend of the series. The main limit of this technique is that it calculates the cycle as the difference between the original series and the trend component. Due to this disadvantage of the method in question, alternative methods were suggested by Baxter \& King (1999), Christiano \& Fitzgerald (1999), and Harvey \& Trimbur (2003).

Baxter - King and Christiano - Fitzgerald filters are band-pass filters since they isolate the short and long-term movements and concentrate on the decomposition of the cycle in the series. Harvey - Trimbur filter performs a multivariate analysis. This analysis obtains economic cycles depending on the cycle that is decomposed using an additive variable (such as GDP) and other variables associated with it. The main advantage of this method is that it extracts the trend and the cycle simultaneously so that it does not change the properties of the series at other frequencies. These two properties cause Harvey - Trimbur filter to be considered as an ideal filter (Note 2). 
Table 1. Contribution of Sub-Sectors to Total Manufacturing Industry Production (2019)

\begin{tabular}{|c|c|c|c|c|c|}
\hline Order & $\begin{array}{l}\text { NACE Rev2 } \\
\text { Group No }\end{array}$ & $\begin{array}{l}\text { CODE used } \\
\text { in this study }\end{array}$ & NACE Rev2 Group Name & $\begin{array}{l}\text { Production Value } \\
\text { (million TL) }\end{array}$ & $\begin{array}{l}\text { Share } \\
(\%)\end{array}$ \\
\hline 1 & 10 & FOOD & Food products & $274,599.8$ & 13.05 \\
\hline 2 & 24 & METAL & Basic metals & $262,763.7$ & 12.49 \\
\hline 3 & 29 & VEHIC & Motor vehicles, trailers and semi-trailers & $195,765.6$ & 9.31 \\
\hline 4 & 13 & TEXT & Textiles & $175,016.7$ & 8.32 \\
\hline 5 & 25 & FABRC & Fabricated metal products & $132,848.4$ & 6.32 \\
\hline 6 & 14 & WEAR & Wearing apparel & $118,364.0$ & 5.63 \\
\hline 7 & 22 & RUBBR & Rubber and plastic products & $113,454.4$ & 5.39 \\
\hline 8 & 20 & CHEMI & Chemicals and chemical products & $106,904.4$ & 5.08 \\
\hline 9 & 23 & OCHEM & Other non-metallic mineral products & $103,132.3$ & 4.90 \\
\hline 10 & 19 & REFIN & Coke and refined petroleum products & $74,250.0$ & 3.53 \\
\hline 11 & 17 & PAPER & Paper and paper products & $57,744.3$ & 2.75 \\
\hline 12 & 31 & FURNI & Furniture & $39,097.0$ & 1.86 \\
\hline 13 & 30 & OTRAN & Other transport equipment & $28,056.3$ & 1.33 \\
\hline 14 & 16 & WOOD & $\begin{array}{l}\text { Wood and wooden and cork } \\
\text { products (except furniture) }\end{array}$ & $27,411.6$ & 1.30 \\
\hline 15 & 15 & LEAT & Leather and related products & $17,977.6$ & 0.85 \\
\hline 16 & 18 & PRESS & $\begin{array}{l}\text { Printing and reproduction } \\
\text { of recorded media }\end{array}$ & $15,195.8$ & 0.72 \\
\hline 17 & 11 & BEVER & Beverages & $14,962.5$ & 0.71 \\
\hline \multirow[t]{2}{*}{18} & 12 & TOBAC & Tobacco products & $9,458.1$ & 0.45 \\
\hline & & & Total Manufacturing Industry & $2,103,805.2$ & 83.99 \\
\hline
\end{tabular}

Source: TUIK, Annual Industrial Product (Prodcom) Statistics, 2019.

The method used by Harvey \& Trimbur (2003) is based on low-pass and band-pass versions of the Butterworth filter. The filter describes a time series with three orthogonal components: the trend component $(\mu)$, the cycle component $(\psi)$, and the non-regular component $(\varepsilon)$, which is considered to be white noise:

$$
y_{t}=\mu_{m, t}+\psi_{n, t}+\varepsilon_{t} \quad(\mathrm{t}=1,2, \ldots, \mathrm{T})
$$

Decomposition of the trend is accomplished through a low pass filter defined depending on time:

$$
B_{m}^{l p}(L)=\frac{1}{1+q^{-1}\left[(1-L)\left(1-L^{-1}\right]^{m}\right.} \quad(m=1,2,3, \ldots)
$$

The parameter $\mathrm{m}$ shows the influence of the components at each frequency, and the filter's gain function $L$ is replaced by $e^{-i \lambda}$ to calculate it:

$$
B_{m}^{l p}(\lambda)=\frac{1}{1+q^{-1}(2-2 \operatorname{Cos} \lambda)^{m}}
$$

Here $\lambda$ is the frequency in radians. Using trigonometric identities in equation (3) and defining $q=\left[2 \operatorname{Sin}\left(\lambda_{l p} / 2\right)\right]^{2 m}$, the trend filter is obtained as follows: 


$$
B_{m}^{l p}(\lambda)=\left[1+\left(\frac{\sin \left(\frac{\lambda}{2}\right)}{\sin \left(\frac{\lambda}{2}\right)}\right)^{2 m}\right]^{-1}
$$

In this equation, it is taken as $0<\lambda_{l p}<\pi$, and $\lambda_{l p}$ shows the frequency in radians for the gain function equal to 0.25 for quarterly data. The reason why the gain function is determined as 0.25 is that the low frequency up to this value is taken into account and the purpose of the filter is to isolate the influence of other frequencies. Thus, the higher the $m$ parameter, the more accurately the effect of other frequencies out of the quarterly is isolated.

Since the cycle component of the series will be at a higher frequency than the trend, it is possible to use another low-frequency Butterworth filter. For this purpose, equation (2) is defined in the context of the lag operator, and the weights are calculated. This equation uses observations obtained by the predicted trend in the middle of a long sample:

$$
B_{m}^{l p}(L)=\sum_{j} w_{j} y_{t+j}
$$

Here $\sum_{j} w_{j}=1$. If the upper limit of the section where the low pass filter is predicted is $\lambda_{l p}=$ $\lambda_{1}$, the calculated weights ensure that the observations at this frequency decrease exponentially in isolating the effect of other frequencies. If the same filter is estimated for high frequencies (such as $\lambda_{2}>\lambda>\lambda_{1}$ ) and the weights of the low-frequency filter are subtracted from the already obtained, a band-pass filter is obtained:

$$
B_{n}^{b p}\left(\lambda ; \lambda_{1}, \lambda_{2}\right)=\left\{1+\left[\frac{\sin \left(\frac{\lambda}{2}\right)}{\sin \left(\frac{\lambda_{2}}{2}\right)}\right]^{2 n}\right\}^{-1}-\left\{1+\left[\frac{\sin \left(\frac{\lambda}{2}\right)}{\sin \left(\frac{\lambda_{1}}{2}\right)}\right]^{2 n}\right\}^{-1}
$$

It should be reminded that here $\lambda_{2}>\lambda_{1}$. The above band-pass filter obtained is more suitable for isolating the effect of frequencies outside the $\lambda_{1}$ and $\lambda_{2}$ parts when $n \rightarrow \infty$. This situation is determined in the gain function for the filter as follows:

$$
B_{n}^{b p}\left(\lambda ; \lambda_{c}\right)=\left\{1+\frac{1}{q}\left[\frac{4\left(\operatorname{Cos} \lambda-\operatorname{Cos} \lambda_{c}\right)}{1+\operatorname{Cos}^{2} \lambda_{c}-2 \operatorname{Cos} \lambda_{c} \operatorname{Cos} \lambda}\right]^{n}\right\}^{-1}
$$

In this equation, parameter $q$ determines the width of the frequency in which the filter is used, and parameter $\lambda_{c}$ indicates the frequency value where the length of the band-pass filter begins.

To extract cycle and trend components, estimating the filter is related to assigning values to parameters and defining other frequencies. For this reason, it is recommended to use generalized filters that guarantee consistency on both components at the frequency used. Thus, the properties of the series at each frequency remain unchanged. The results to be obtained for the band-pass filter by making use of the low pass filter are not the same as the results obtained by simultaneous estimation of generalized filters. This is due to the improper selection of parameters (e.g. too small value for $m$ ). This situation indicates that the low pass filter gain function interferes with the frequency properties of the trend and cycle components 
of the series. Therefore, when we estimate the second filter to extract the cycle from the results of the first filter, it means that we are actually working with a series with a frequency whose cyclical component has already changed. In this case, the only way to prevent distortion in frequency by estimating low and band-pass filters separately is to realize the gain function closest to the gain function of the ideal filter. Therefore, the simultaneous estimation of generalized filters such as the Butterworth filter (although it does not mean using an ideal filter in the strict sense) is considered a preferable alternative, as it creates consistent estimates of unobservable components.

If the sub-sectors of production have cycles similar to total production, the Butterworth filter can be used to evaluate the existence of economic (common) cycles, as it allows to determine this. Thus, if fluctuations occurring simultaneously in several sectors at a certain frequency can be determined, economic cycles occur. However, if each of the sectors fluctuates in different frequencies, idiosyncratic cycles occur (Pelagatti, 2005).

In this study, the filter developed by Harvey \& Trimbur (2003) based on the Butterworth filter is estimated. In this process, the common cycle for the manufacturing industry and the sector-specific cycles for the manufacturing industry sub-sectors are estimated using the method suggested by Pelagatti (2005) and Valle et al. (2004). This method requires the decomposition of the cycle common to all series in the first stage, and the industry-specific trend and cycle by using Butterworth filter for sub-sector data that is cleared of the common cycle in the second stage.

The representation of this multivariate structural model for the period $t=1$ is as follows:

$$
y_{k t}=\mu_{k t}+\delta_{k} \psi_{t}+\xi_{k t}
$$

Here, $y_{k t}$ denotes the production for the $k$-th sub-sector, the $\mu_{k t}$ trend component and the common cycle for the whole manufacturing industry. $\delta_{k}$ indicates the weight of the common cycle for each sector and $\xi_{k t}$ indicates the irregular component. It is accepted that $\xi_{k t}$ has traditionally the property of $\xi_{k t} \sim N\left(0, \sigma_{k \xi}^{2}\right)$ and does not exhibit serial correlation and correlation with other sub-production sectors.

According to Valle et al. (2004), the common cycle is defined as an autoregressive model of polynomial coefficients with a complex root. This is accomplished by defining the cycle as a trigonometric function:

$$
\left(\begin{array}{l}
\psi_{t} \\
\psi_{t}^{*}
\end{array}\right)=\theta\left(\begin{array}{cc}
\operatorname{Cos} \lambda & \operatorname{Sin} \lambda \\
-\operatorname{Sin} \lambda & \operatorname{Cos} \lambda
\end{array}\right)\left(\begin{array}{l}
\psi_{t-1} \\
\psi_{t-1}^{*}
\end{array}\right)+\left(\begin{array}{c}
\varsigma_{t} \\
\varsigma_{t}^{*}
\end{array}\right)
$$

where

$$
\begin{array}{r}
\varsigma_{t} \sim N\left(0, \sigma_{\varsigma}^{2}\right) \\
\zeta_{t}^{*} \sim N\left(0, \sigma_{\zeta^{*}}^{2}\right)
\end{array}
$$

In equation (9), $\zeta_{t}$ and $\zeta_{t}^{*}$ are independent for all $t$ 's and parameter $\theta$ is the factor that 
determines the decay in the lagged variable where $\theta \in(0,1]$. If the variance of $\varsigma$ is $\sigma_{\varsigma}^{2}=\left(1-\theta^{2}\right) \sigma_{\psi}^{2}$, parameter $\theta$ guarantees that $\psi$ process is stationary.

Regarding model parameters, trend and cycle components can be predicted in one step using the Kalman filter. Because it is possible to write the space state form of equation (8). However, following this method, Valle et al. (2004) obtained inconsistent values for $\lambda_{c}$. In order to predict the common cycle in the first stage, some parameters must therefore be determined in advance.

According to Pelagatti (2005), the frequency associated with cycles for quarterly data is in the range of $[0.20,1.05]$ and it would be appropriate to determine $\lambda_{c}$ as 0.5 . This value is the specific frequency that the low pass filter will accept. Similarly, for the quarterly data, the author proposes to specify $m, \rho, n$ and $\delta$ values. Accepting $m=1$ allows $\psi_{t}$ to determine the fluctuation common to all series with a high gain function. Similarly, the values of $\rho=0.7$ and $n=4$ are kept constant in two estimation stages. Finally, the value of $\delta$ is normalized to 1 for each of the sub-sectors. Thus, it is measured in the same unit as the common cycle (in our case, $\delta_{t m p}=1$, tmp refers to the total manufacturing industry production).

After determining the common cycle for all sectors, the idiosyncratic cycle is decomposed. For this, the common cycle in the original series is cleared as follows:

$$
\tilde{y}_{k t}=y_{k t}-\delta_{k} \psi_{t}
$$

Production series in common-cycle-free sub-sectors are decomposed into trend and idiosyncratic cycle components using the parameter values previously defined with the generalized Butterworth filter.

\section{Estimation Results}

\subsection{General Properties of Common Cycle and Idiosyncratic Cycles}

OxMetrics 7.0 software and programming code (SSFPACK) developed by S. J. Koopman, N. Shepard and J.A. Doornik were used to estimate common and idiosyncratic cycles. When looking at the results in general, it is possible to determine the characteristics of the common cycle and the cycles specific to the sub-sectors included in the research. This assessment can be made in the context of determining the periods of expansion and contraction and the average duration of the cycles. For this purpose, periods were determined according to the points where the production reached the highest and lowest value, and thus the average duration of the expansion and contraction periods for each sector was calculated. The algorithm suggested by Pelagatti (2005) was used. Accordingly, the periods when the cycle series is above zero constitute the periods of expansion and the periods when it is below zero constitute the recession periods. In Figure 1, the gray areas indicate the periods of contraction in production, while the white areas indicate the expansion periods. It is possible to identify some key findings according to the chart: (i) Common cycle produces results in line with the economic crises $(2000-2001,2008,2018)$ and contraction processes that followed in Turkish economy during the analyzing period. (ii) Common cycle estimated for the entire 


\section{Macrothink}

manufacturing industry exhibits consistent results for expansion periods (especially in 2004-2008 and 2010-2011 periods) experienced in Turkey. (iii) While the expansion periods are short, the contraction periods are longer. This indicates that the manufacturing industry has an important role in discussions where total production followed a $\mathrm{W}$ process in the economy. Apart from these, the chart also proves the relationship between economic growth and its instability. As is known, there is an inverse relationship between the average growth rate and the length of the cycle (see Figure 2).

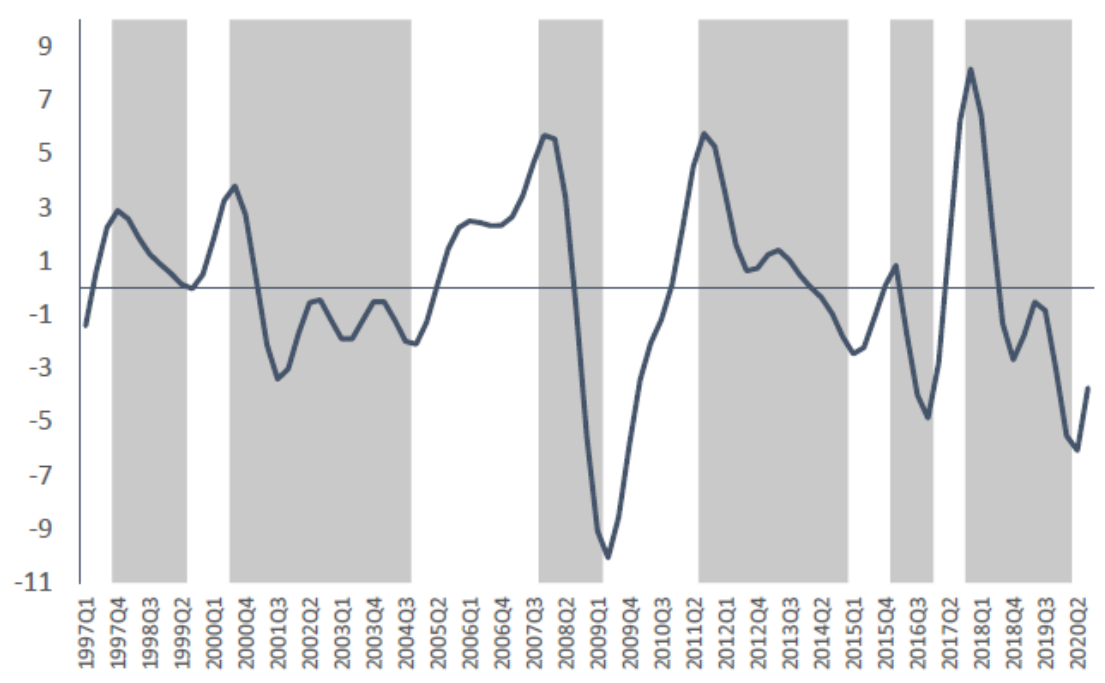

Figure 1. Cycle Component of Manufacturing Industry Production

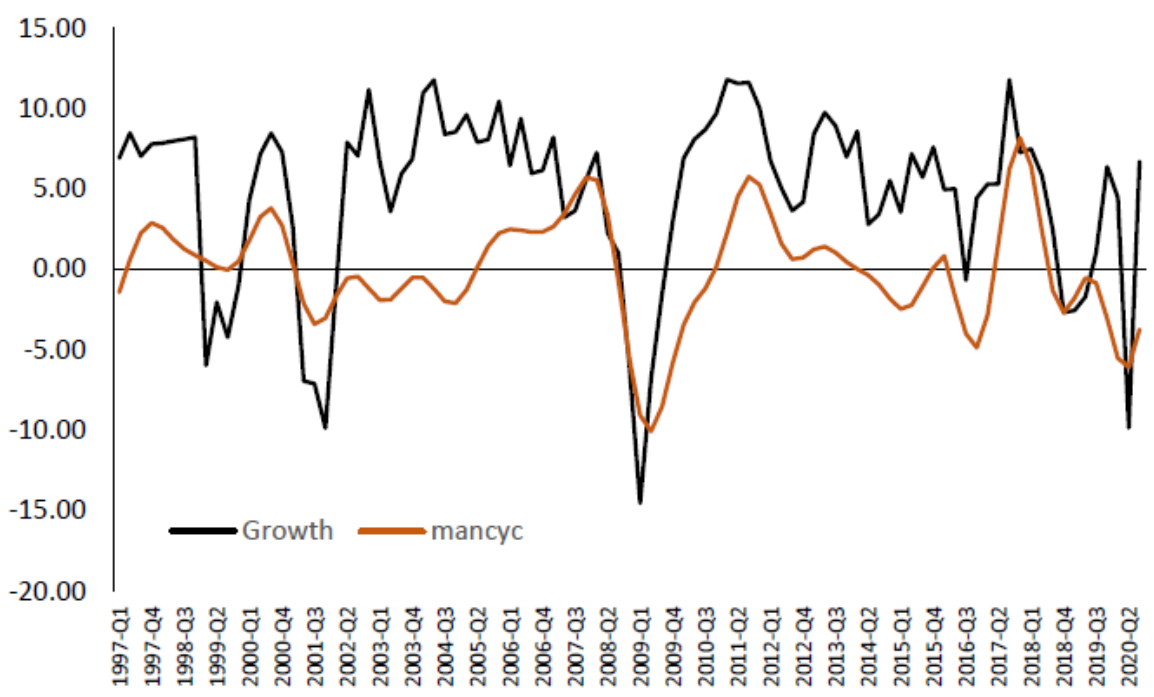

Figure 2. Annual Growth Rate and Manufacturing Industry Common Cycle

The obtained estimation results allow us to determine that there are 6 common cycles in manufacturing industry production. These cycles occur in periods of expansion and contraction that occur in different sizes and an irregular structure. According to Table 2, these 
common cycles for all manufacturing industry sectors have an average length of 16 quarters (4 years). Male (2010), in his study examining the business cycles of 32 developing countries through GDP data, determines the average cycle duration as 21 quarters. In studies specific to Turkey, this duration ranges from 8 to 21 quarters despite the existence of differences in the sample period, methodology, reference series and frequency. For example, this duration is estimated 21 quarters by Asik (2020), 20 quarters by Alp et. al. (2012), 17 quarters by Binici et. al. (2016) and 8 quarters by Ozkan \& Erden (2007) for Turkey. Covering the 1988-2004 period, the average duration of cycles (shortest 2, longest 4 quarters) determined by Senyuz (2002) and Saltoglu et al. (2003) does not comply with the widely accepted business cycle definition made by Bry - Boschan (1971).

Table 2. Properties of Common Cycle in Manufacturing Industry

\begin{tabular}{|c|c|c|c|c|c|}
\hline \multicolumn{3}{|c|}{ Cycle Process } & \multicolumn{3}{|c|}{ Duration (in quarters) } \\
\hline Through & Peak & Through & Expansion & Contraction & Cycle \\
\hline 1996.I & 1997.IV & 1999.III & 7 & 7 & 14 \\
\hline 1999.III & 2000.III & 2004.IV & 4 & 16 & 20 \\
\hline 2004.IV & 2007.IV & 2009.II & 12 & 6 & 18 \\
\hline 2009.II & 2011.III & 2015.I & 9 & 14 & 23 \\
\hline 2015.I & 2015.IV & 2016.IV & 3 & 4 & 7 \\
\hline 2016.IV & 2017.IV & 2020.II & 4 & 10 & 14 \\
\hline \multicolumn{3}{|c|}{ AVERAGE } & 6.5 & 9.5 & 16 \\
\hline
\end{tabular}

According to Table 2, the average expansion period of the cycles observed in the Turkish manufacturing industry is 6.5 quarters (26 months) while the average recession period is 9.5 quarters (38 months). The longest of the expansion periods is the 12 -quarter period experienced after the 2000-2001 economic crisis. Similarly, the longest contraction period is the 16-quarter contraction experienced during the same crisis period. The contraction started in the third quarter of 2000 and continued until the 4th quarter of 2004. These findings are in line with the theoretical expectations we expressed earlier.

A - J panels of Table 3 have been prepared to examine the same process by sub-sectors. According to the table, it is seen that the shortest sectoral cycle is in the manufacture of wearing apparel with 11.6 quarters (about 35 months), the longest cycle is in the manufacture of basic metals and manufacture of rubber and plastic products with about 20 quarters (about 60 months). In other sub-manufacturing sectors, the average duration of cycles is around 15 quarters (about 45 months). On the other hand, the sub-sectors with the highest number of cycles due to the shortness of cycle duration are textile products, wearing apparel manufacturing. While the manufacturing industry is subject to 6 cycles in total, the number of cycles in sub-sectors of textiles and wearing apparel is 8 and 9 , respectively. 
Table 3. Properties of Idiosyncratic Cycles

\begin{tabular}{|c|c|c|c|c|c|c|c|c|c|c|c|}
\hline \multicolumn{3}{|c|}{ A: FOOD } & \multirow{2}{*}{$\begin{array}{l}\text { Contract. } \\
\text { Duration }\end{array}$} & \multirow{2}{*}{$\begin{array}{l}\text { Expansion } \\
\text { Duration }\end{array}$} & \multirow{2}{*}{$\begin{array}{l}\text { Cycle } \\
\text { Durati. }\end{array}$} & \multicolumn{3}{|c|}{ B: METAL } & \multirow{2}{*}{$\begin{array}{l}\text { Contract. } \\
\text { Duration }\end{array}$} & \multirow{2}{*}{$\begin{array}{l}\text { Expansion } \\
\text { Duration }\end{array}$} & \multirow{2}{*}{$\begin{array}{l}\text { Cycle } \\
\text { Durati. }\end{array}$} \\
\hline Peak & Thro & Peak & & & & Peak & \begin{tabular}{|l|} 
Thro \\
\end{tabular} & Peak & & & \\
\hline 97.IV & 01.IV & 03.IV & 12 & 8 & 20 & 99.IV & 00.IV & 01.II & 5 & 3 & 7 \\
\hline 03.IV & 04.IV & 06.I & 4 & 5 & 9 & 01.II & 02.I & 03.I & 3 & 4 & 7 \\
\hline 06.I & 09.II & 11.IV & 13 & 10 & 23 & 03.I & 05.III & 07.IV & 10 & 9 & 19 \\
\hline $11 . \mathrm{IV}$ & 12.IV & 13.IV & 4 & 4 & 8 & 07.IV & 10.I & 14.I & 9 & 16 & 25 \\
\hline 13.IV & 15.IV & 18.I & 8 & 9 & 17 & 14.I & 15.IV & 18.II & 7 & 10 & 17 \\
\hline \multicolumn{6}{|c|}{ the } & 18.II & 19.III & & 5 & & \\
\hline \multicolumn{3}{|c|}{ AVERAGE } & 8.2 & 7.2 & 15.4 & \multicolumn{3}{|c|}{ AVERAGE } & 6.5 & 8.4 & 15 \\
\hline \multicolumn{3}{|c|}{ C: VEHIC } & Contract. & Expansion & Cycle & \multicolumn{3}{|c|}{ D: TEXT } & Contact. & Expansion & Cycle \\
\hline Peak & Thro & Peak & Duration & Duration & Durati. & Peak & Thro & Peak & Duration & Duration & Durati. \\
\hline 97.IV & 99.II & 00.II & 6 & 4 & 10 & 97.IV & 99.I & $00 . I$ & 5 & 4 & 9 \\
\hline 00.II & 01.IV & 04.III & 6 & 11 & 17 & 00.I & 01.I & 02.IV & 4 & 7 & 11 \\
\hline 04.III & 07.I & 08.I & 10 & 4 & 14 & 02.IV & 05.III & 07.I & 11 & 6 & 17 \\
\hline 08.I & 09.I & 11.III & 4 & 10 & 14 & 07.I & 08.III & 10.II & 6 & 7 & 13 \\
\hline \multirow{5}{*}{\multicolumn{3}{|c|}{ 11.III }} & 35 & & & $10 . \mathrm{II}$ & 11.III & 14.II & 5 & 11 & 16 \\
\hline & & & & & & 14.II & 15.I & $16 . I$ & 3 & 4 & 7 \\
\hline & & & & & & $16 . \mathrm{I}$ & $18 . \mathrm{II}$ & 19.II & 9 & 4 & 13 \\
\hline & & & & & & 19.II & $20 . I I$ & & 4 & & \\
\hline AVERAGE & & & 8.2 & 7.2 & 15.4 & \multicolumn{3}{|c|}{ AVERAGE } & 6.5 & 8.4 & 15 \\
\hline \multicolumn{3}{|c|}{ E: FABRC } & Contract. & Expansion & Cycle & \multicolumn{3}{|c|}{ F: WEAR } & Contract. & Expansion & Cycle \\
\hline Peak & Thro & Peak & Duration & Duration & Durati. & Peak & \begin{tabular}{|l|} 
Thro \\
\end{tabular} & Peak & Duration & Duration & Durati. \\
\hline 97.III & 98.II & 01.III & 3 & 13 & 16 & $96 . I$ & 97.III & 98.II & 6 & 3 & 9 \\
\hline 01.III & 04.II & 05.III & 11 & 5 & 16 & 98.II & 99.I & 01.III & 3 & 10 & 13 \\
\hline 05.III & $10 . \mathrm{III}$ & 13.I & 20 & 10 & 30 & 01.III & 04.I & 05.III & 10 & 6 & 16 \\
\hline 13.I & 15.III & 17.IV & 10 & 9 & 19 & 05.III & 06.III & 07.II & 4 & 3 & 7 \\
\hline 17.IV & 18.IV & & 4 & & & 07.II & 08.II & 09.II & 4 & 4 & 8 \\
\hline & & & & & & 09.II & 11.III & 12.III & 9 & 4 & 13 \\
\hline & & & & & & 12.III & 13.IV & 16.I & 5 & 9 & 14 \\
\hline & & & & & & 16.I & 18.II & 19.II & 9 & 4 & 13 \\
\hline & & & & & & 19.II & $20 . I I$ & & 4 & & \\
\hline AVER & $\mathrm{GE}$ & & 9.6 & 9.25 & 20.25 & AVER & $\mathrm{GE}$ & & 6 & 5.38 & 11.63 \\
\hline G: RUI & BR & & Contract. & Expansion & Cycle & $\mathrm{H}: \mathrm{CH}$ & $\mathrm{MI}$ & & Contract. & Expansion & Cycle \\
\hline Peak & Thro & Peak & Duration & Duration & Durati. & Peak & Thro & Peak & Duration & Duration & Durati. \\
\hline 98.III & 00.I & 01.I & 7 & 4 & 11 & 98.I & 98.IV & 00.I & 3 & 4 & 7 \\
\hline $01 . \mathrm{I}$ & $02 . I I$ & $05 . \mathrm{II}$ & 5 & 12 & 17 & 00.I & 03.II & 06.I & 13 & 11 & 24 \\
\hline 05.II & 08.III & 11.I & 13 & 10 & 23 & 06.I & 08.III & 09.IV & 10 & 5 & 15 \\
\hline 11.I & 15.III & 18.I & 18 & 10 & 28 & 09.IV & 13.I & 14.II & 13 & 5 & 18 \\
\hline 18.I & 19.III & & 6 & & & 14.II & 17.II & 18.III & 12 & 5 & 17 \\
\hline & & & & & & 18.III & 19.II & & 3 & & \\
\hline AVER & $\mathrm{GE}$ & & 9.8 & 9 & 19.75 & AVER & GE & & 9 & 6 & 16.2 \\
\hline I: $\mathrm{OCH}$ & EM & & Contract. & Expansion & Cycle & J: REF & & & Contract. & Expansion & Cycle \\
\hline Peak & Thro & Peak & & & & Peak & Thro & Peak & Duration & Duration & Durati. \\
\hline 98.IV & 99.IV & 00.III & 4 & 3 & 7 & 97.II & $98 . I$ & 99.I & 3 & 4 & 7 \\
\hline 00.III & 04.II & 06.IV & 15 & 10 & 25 & 99.I & 00.I & $02 . I$ & 4 & 8 & 12 \\
\hline $06 . I V$ & 07.IV & 08.IV & 4 & 4 & 8 & 02.I & 05.IV & 08.III & 15 & 11 & 26 \\
\hline 08.IV & 11.IV & 13.IV & 12 & 8 & 20 & 08.III & 09.IV & 11.I & 5 & 5 & 10 \\
\hline 13.IV & 15.I & 18.I & 5 & 12 & 17 & 11.I & 14.II & 15.III & 13 & 5 & 18 \\
\hline $18 . \mathrm{I}$ & 19.III & & 6 & & & 15.III & 18.II & 19.III & 11 & 6 & 17 \\
\hline AVER & GE & & 7.67 & 7.4 & 15.4 & AVER & AGE & & 8.5 & 6.5 & 15 \\
\hline
\end{tabular}

\subsection{Relationship between Common and Idiosyncratic Cycles}

Signals separated by the Butterworth filter are given in A-J panels in Figure 3. The graphic on the left in each panel in the figure shows the production dynamics in the sub-manufacturing sectors and the trend produced by the low-pass filter. The graph on the right of each panel compares the manufacturing industry common cycle predicted by the band-pass filter with 


\section{Ml Macrothink}

Business and Economic Research ISSN 2162-4860 2021, Vol. 11, No. 2

the industry-specific cycle. In general, the production in the sub-sectors displays an increasing trend with two main exceptions. The first of these is the downward trend observed in the manufacture of textile products in the period of $2002-2009$, the other is the fluctuating trend observed in the manufacture of coke and refined petroleum products throughout the period. Considering that the dependence on foreign trade is intense in both sectors, it is possible to say that the production dynamics in these sectors are based on the developments in international markets rather than the internal dynamics of the manufacturing industry.

A. Manufacture of Food Products (FOOD)

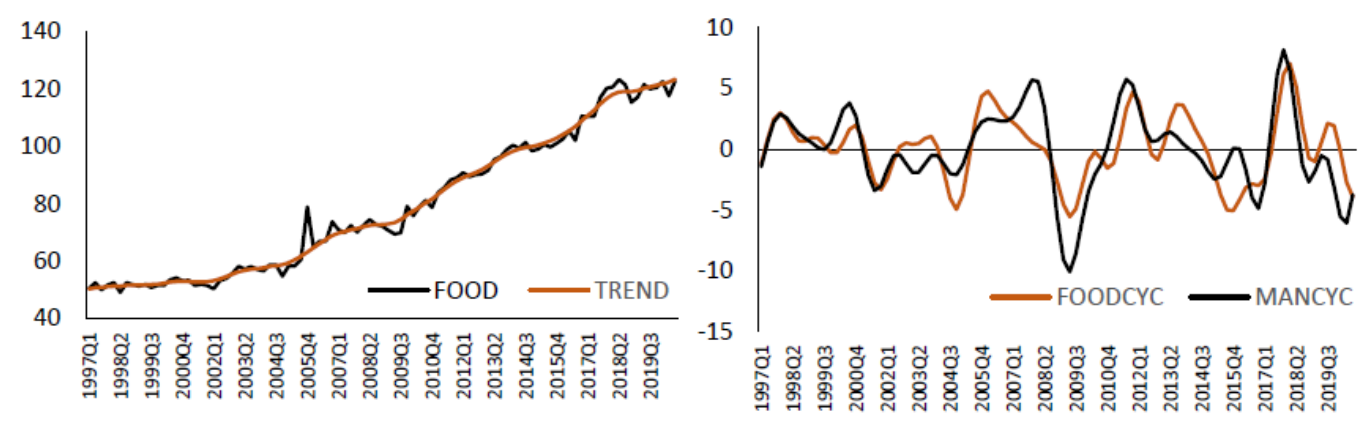

B. Manufacture of Basic Metals (METAL)
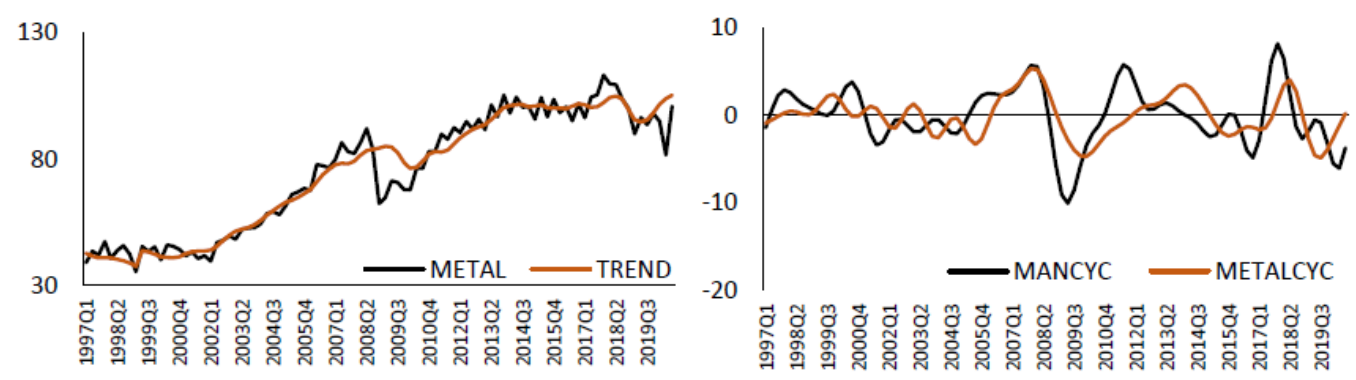

C. Manufacture of Motor Vehicles, Trailers and Semi-Trailers (VEHIC)
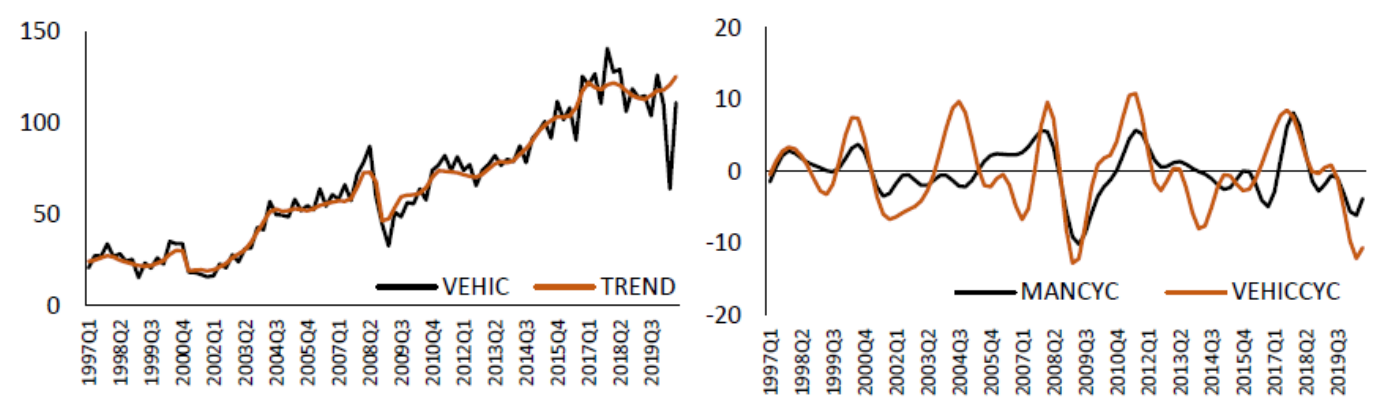

D. Manufacture of Textiles (TEXT)
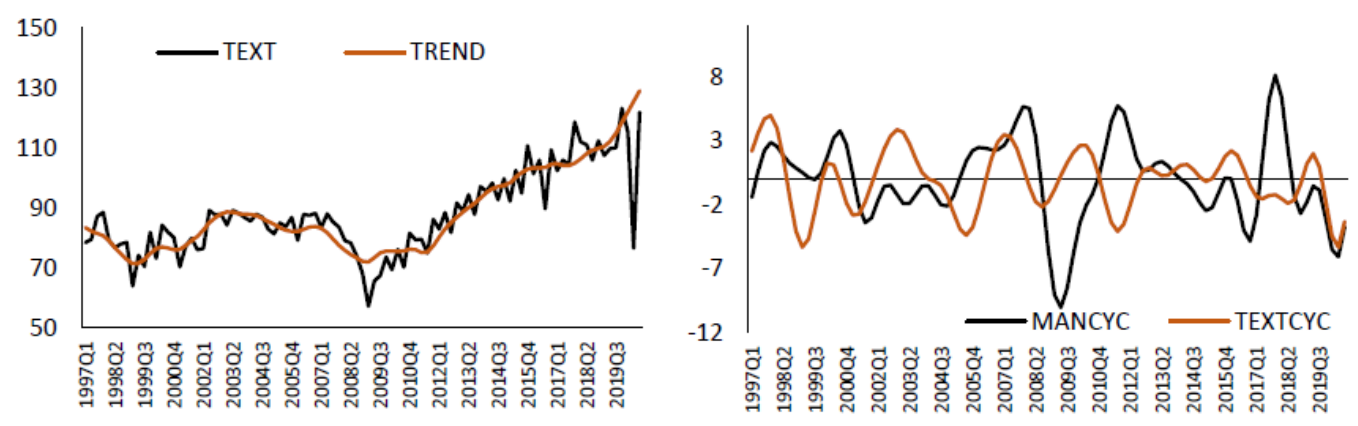
E. Manufacture of Fabricated Metal Products (FABRC)

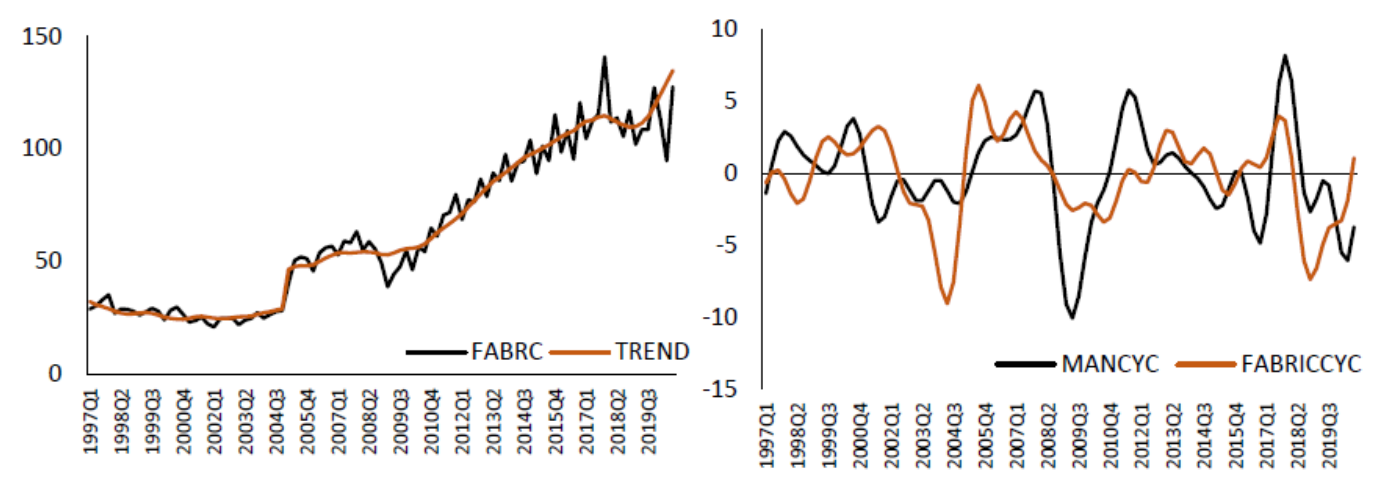

F. Manufacture of Wearing Apparel (WEAR)

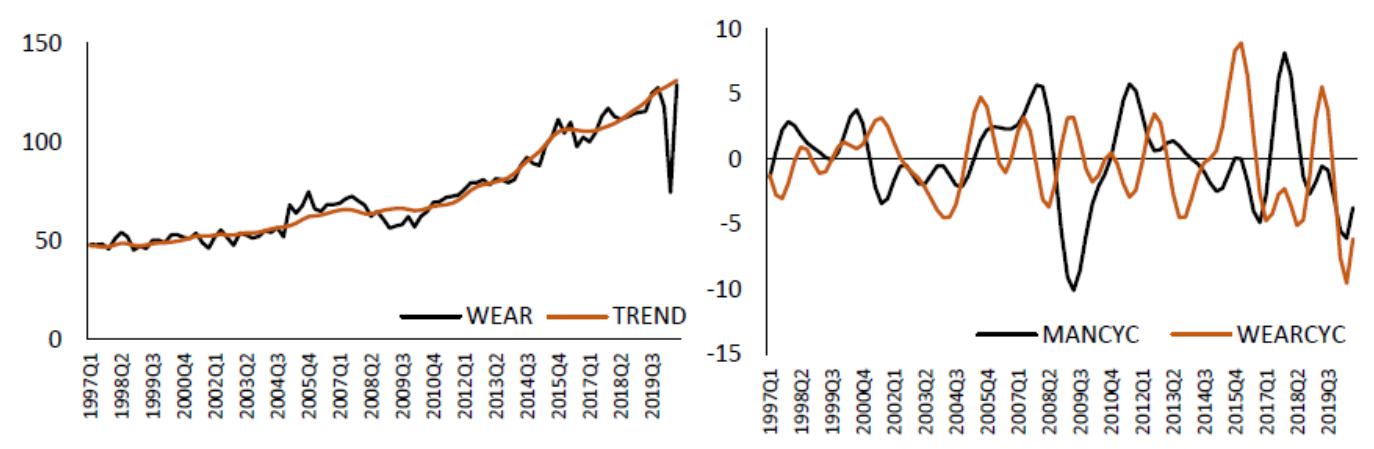

G. Manufacture of Rubber and Plastic Products (RUBBR)
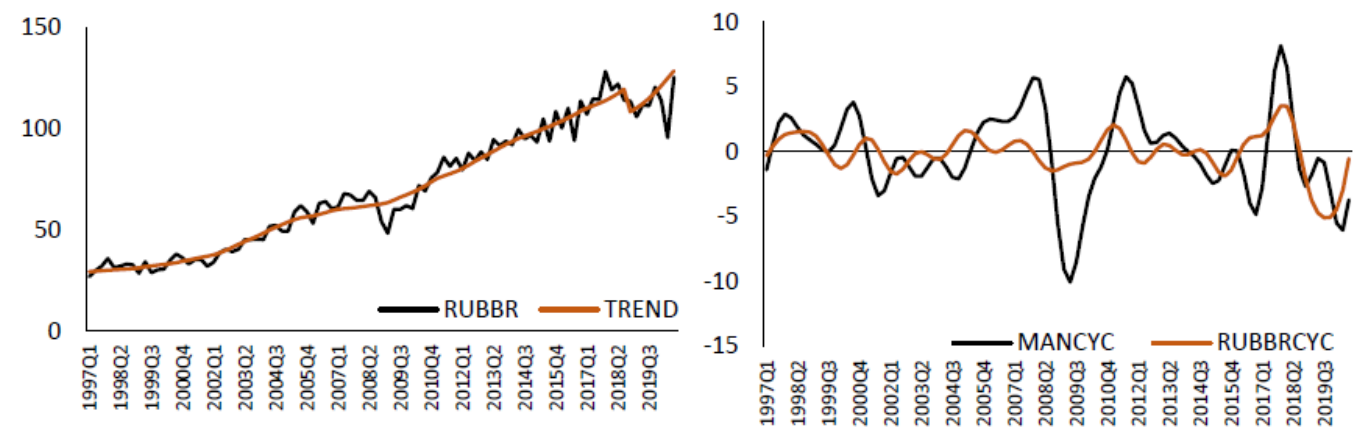

H. Manufacture of Chemicals and Chemical Products (CHEMI)

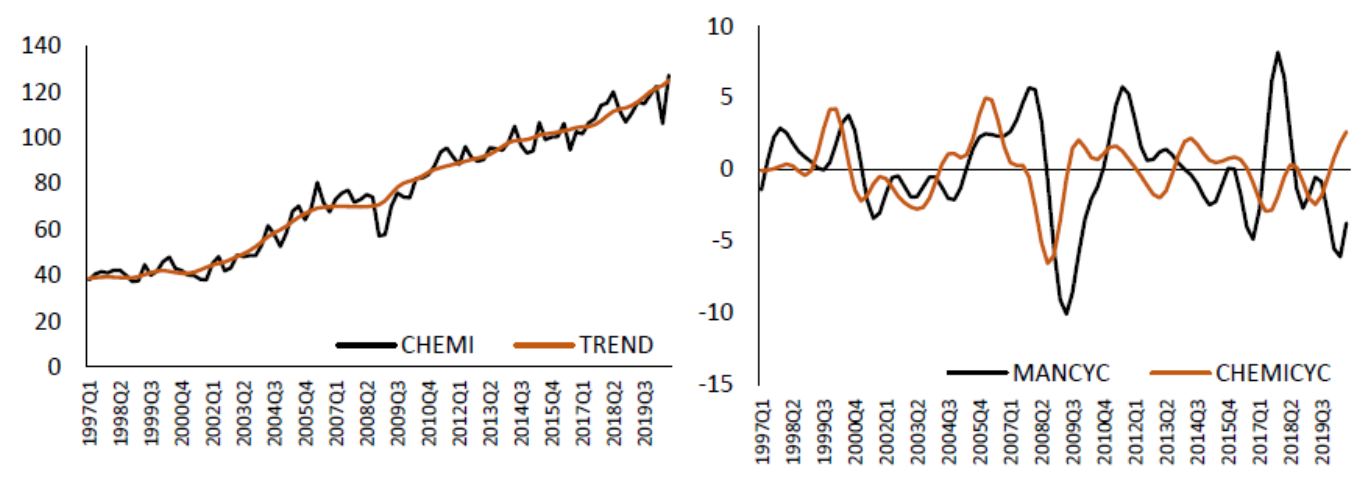


I. Manufacture of Other Non-metallic Mineral Products (OCHEM)

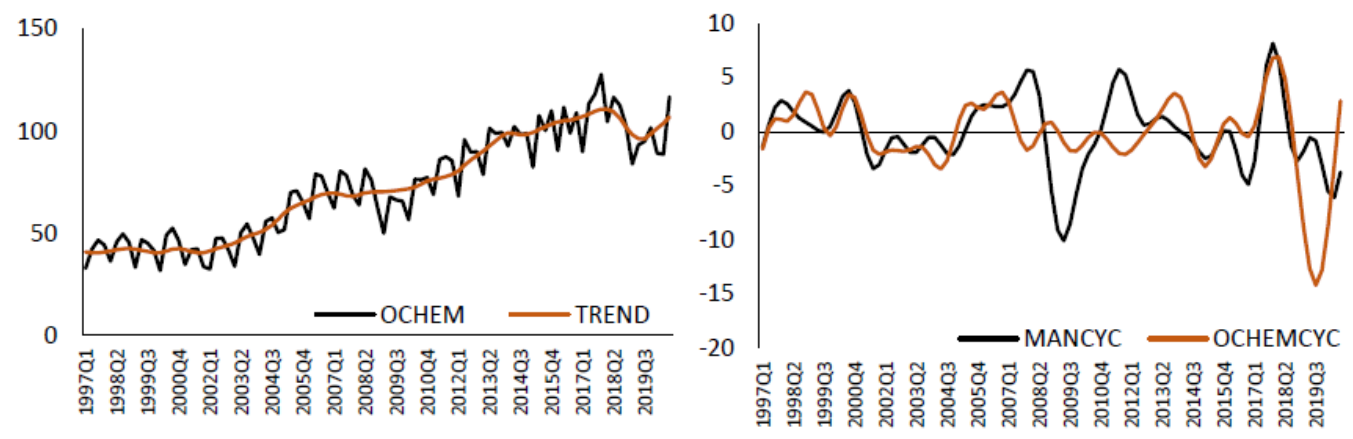

J. Manufacture of Coke and Refined Petroleum Products (REFIN)

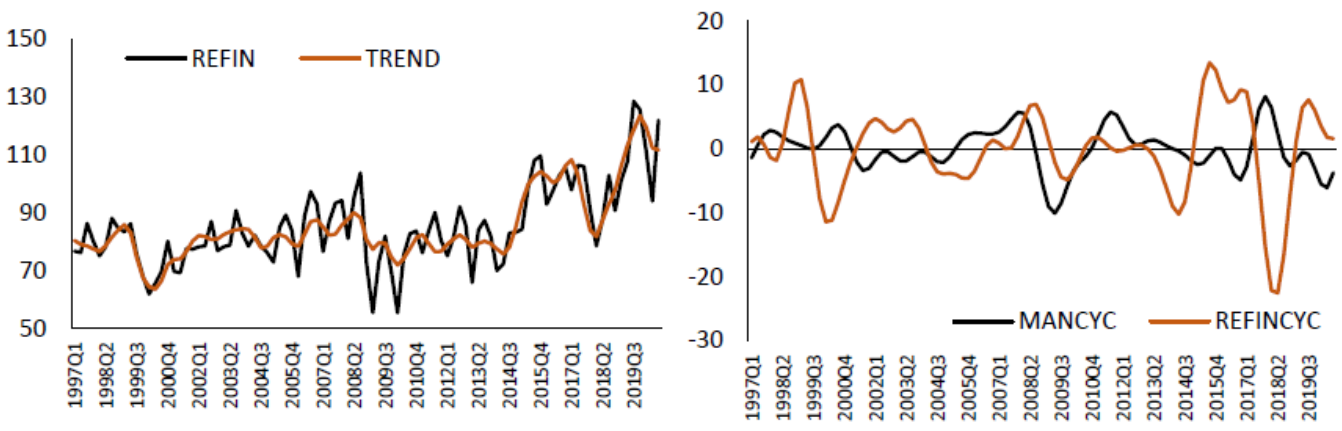

Figure 3. Production Dynamics in Sub-Sectors and Idiosyncratic Cycles

Idiosyncratic cycles estimated for sub-manufacturing sectors are considerably affected by fluctuations that concern the whole economy. All sub-sectors react in the same direction to the economic turbulence experienced in 2001, 2008 and 2018. While the severity of the production contractions that occur varies among sub-sectors, idiosyncratic cycles are compatible with the common cycle. Despite this general trend, cycles in the textile, wearing and refined petroleum products sub-sectors differ significantly from the common cycle. Cycles in textile products and wearing apparel sub-sectors exhibit an oscillation independent of the manufacturing industry common cycle. There are two reasons for this. First, textile products are one of Turkey's main export products. Therefore, producers may turn to international markets in the face of a contraction in domestic demand. On the other hand, export becomes attractive because periods of country-specific economic turbulence often result in an increase in foreign currency prices (depreciation of the domestic currency). A similar situation also applies for refined petroleum products. Here, too, as the sector is completely dependent on imports, the depreciation of the domestic currency creates a deterrent effect and creates sector-specific production fluctuations.

The sector displaying an interesting trend among the sub-manufacturing sectors examined is the manufacture of food products. As will be remembered, the food sector is the sub-sector with the highest share in total manufacturing industry production. It is possible to say that the idiosyncratic cycle is fully compatible with the common cycle, except for 2015. As a matter of fact, the lowest rate in Table 4, which shows the ratio of the idiosyncratic cycles' variance 
observed in the sub-sectors to that of the common cycle, belongs to the food products manufacturing sector. According to the table, the sectors in which the variance ratio is greater than 1 (motor vehicles, refinery products and other non-metallic mineral products) are quite limited. This situation indicates that the relationship between idiosyncratic cycles and common cycle should be examined in more detail.

Table 4. Ratio of Idiosyncratic Cycle Variance to Common Cycle Variance

\begin{tabular}{|l|l|}
\hline Sub Sector & Variance Ratio \\
\hline Food products (FOOD) & 0,216667 \\
\hline Basic metals (METAL) & 0,494162 \\
\hline Motor vehicles, trailers and semi-trailers (VEHIC) & 2,647560 \\
\hline Textiles (TEXT) & 0,514408 \\
\hline Fabricated metal products (FABRC) & 0,826226 \\
\hline Wearing apparel (WEAR) & 0,939367 \\
\hline Rubber and plastic products (RUBBR) & 0,230980 \\
\hline Chemicals and chemical products (CHEMI) & 0,396333 \\
\hline Other non-metallic mineral products (OCHEM) & 1,119202 \\
\hline Coke and refined petroleum products (REFIN) & 3,985963 \\
\hline
\end{tabular}

The common and industry-specific cycles we estimated may hide the lag and lead relationship among the production dynamics in these sectors (Kydland \& Zaragoza, 1997). Therefore, we need an alternative perspective that involves the non-contemporaneous connection among cycles. The commonly used criterion to examine the relationship between cycles in different lags and leads is cross-correlation coefficients. The A-J panels of Figure 4 present the cross-correlation coefficients between the manufacturing industry common cycle and idiosyncratic $(\mathrm{t}-\mathrm{i})$ and $(\mathrm{t}+\mathrm{i})$ cycles. Dashed lines in the relevant graphs represent \pm 2 standard error bands. When the graphics are analyzed in terms of lag structure, most of the cross-correlations in the sub-sectors of motor vehicles (VEHIC), textiles (TEXT), wearing apparel (WEAR), rubber and plastic products (RUBBR), other non-metallic mineral products (OCHEM) and refined petroleum products (REFIN) do not carry adequately statistical significance. A similar situation in terms of leading relationships applies to textiles (TEXT), fabricated metal products (FABRC), wearing apparel (WEAR), chemicals and chemical products (CHEMI), other non-metallic mineral products (OCHEM) and refined petroleum products (REFIN). In this case, the relevant cross-correlation functions show that the cycles observed in the sub-sectors of food products (FOOD), basic metals (METAL), fabricated metal products (FABRC) and chemicals and chemical products (CHEMI) exhibit a lagged correlation with the manufacturing industry common cycle. On the other hand, it is understood that the idiosyncratic cycles of food products (FOOD), basic metals (METAL), motor vehicles, trailers and semi-trailers (VEHIC) and rubber and plastic products (RUBBR) sub-sectors have a leading correlation with the manufacturing industry common cycle.

This result obtained from the cross-correlation functions can be checked by examining whether the average contraction and expansion durations in the relevant sub-sectors exhibit 
lag or lead over the common cycle. Table 5 has been prepared for this purpose and shows the average lag and lead times of idiosyncratic cycle turning points relative to those of the common cycle. First of all, values less than 1 in absolute terms have been excluded from the evaluation and accepted as contemporaneous since they represent a very short time for an area with production dynamics like the manufacturing industry. On the other hand, within the framework of the preparation logic of the table, positive values refer to lags while negative values express leads. Accordingly, these characteristics of sub-sectors like basic metals, rubber and plastic products as the lagging sectors and sub-sectors like food products, basic metals as the leading sectors, are confirmed. The lag and lead relationship exhibited by the other sub-sectors in Table 5 contradicts the cross-correlation analysis.

\begin{tabular}{|c|c|c|c|c|c|c|c|c|c|c|c|}
\hline \multicolumn{3}{|c|}{ A: Food Products } & \multicolumn{3}{|c|}{ B: Basic Metals } & \multicolumn{4}{|c|}{ C: Motor Vehicles } & & \\
\hline $\mathrm{rec}(-1)$ & MANCYC,FOOD & 130 & leaso & A & & $1 \quad 129$ & 1 lesa & CYC,VEACCYC & NCYC,VEHCCYCI & $\begin{array}{ll}1 & 129 \\
\end{array}$ & leas \\
\hline 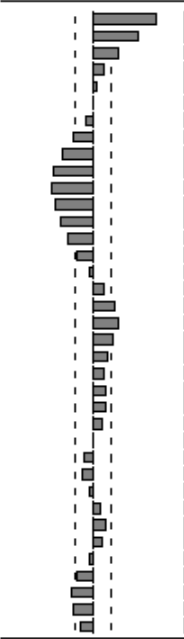 & 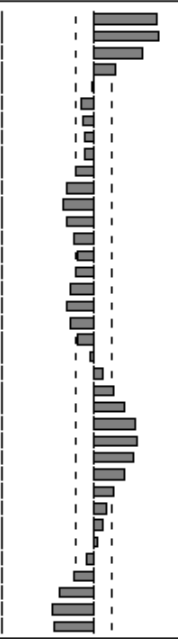 & 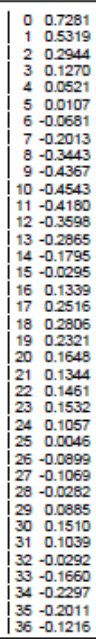 & 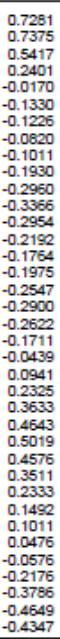 & 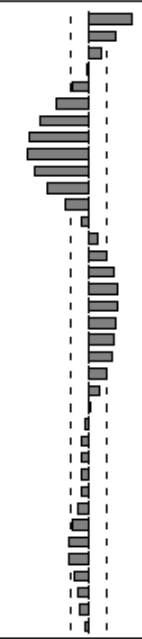 & 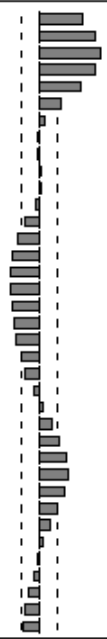 & 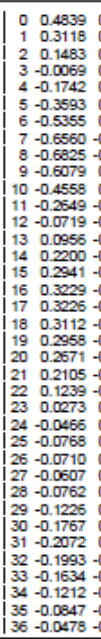 & 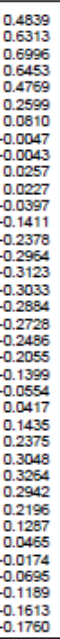 & 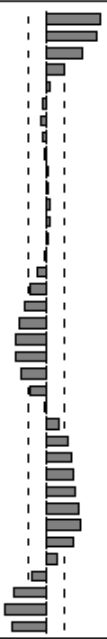 & 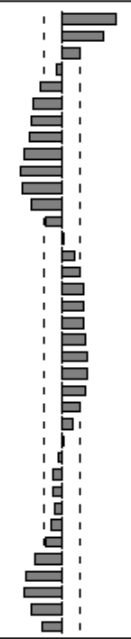 & 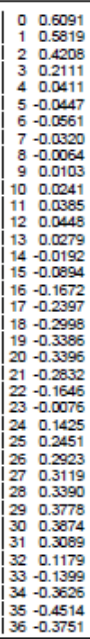 & 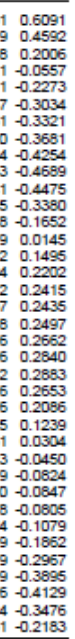 \\
\hline
\end{tabular}

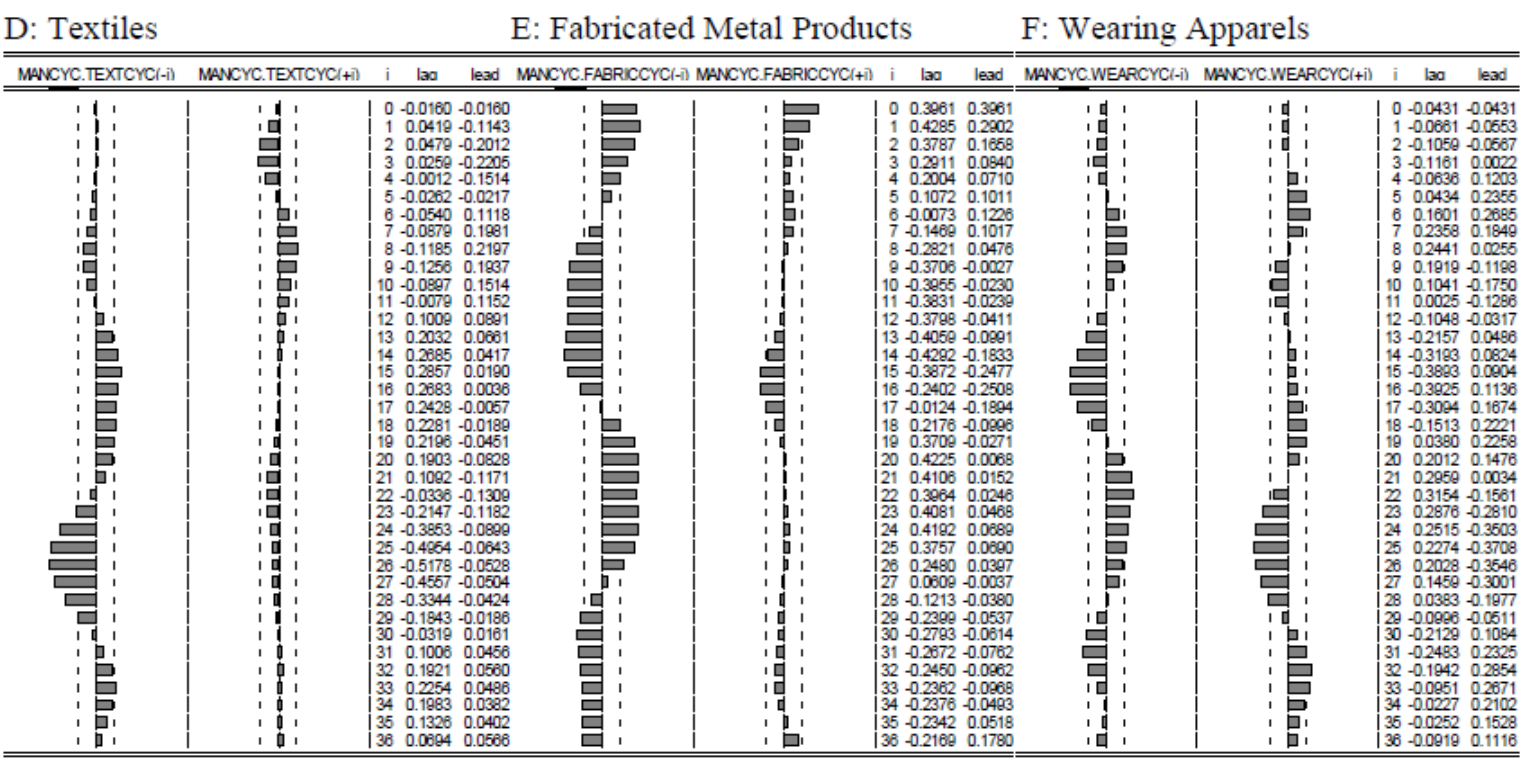




\section{MInstitute Macrothink}

Business and Economic Research

ISSN 2162-4860

2021, Vol. 11, No. 2

G: Rubber and Plastic Products $\quad \mathrm{H}$ : Chemicals and Chemical Prod. I: Other Non-Metallic Minerals

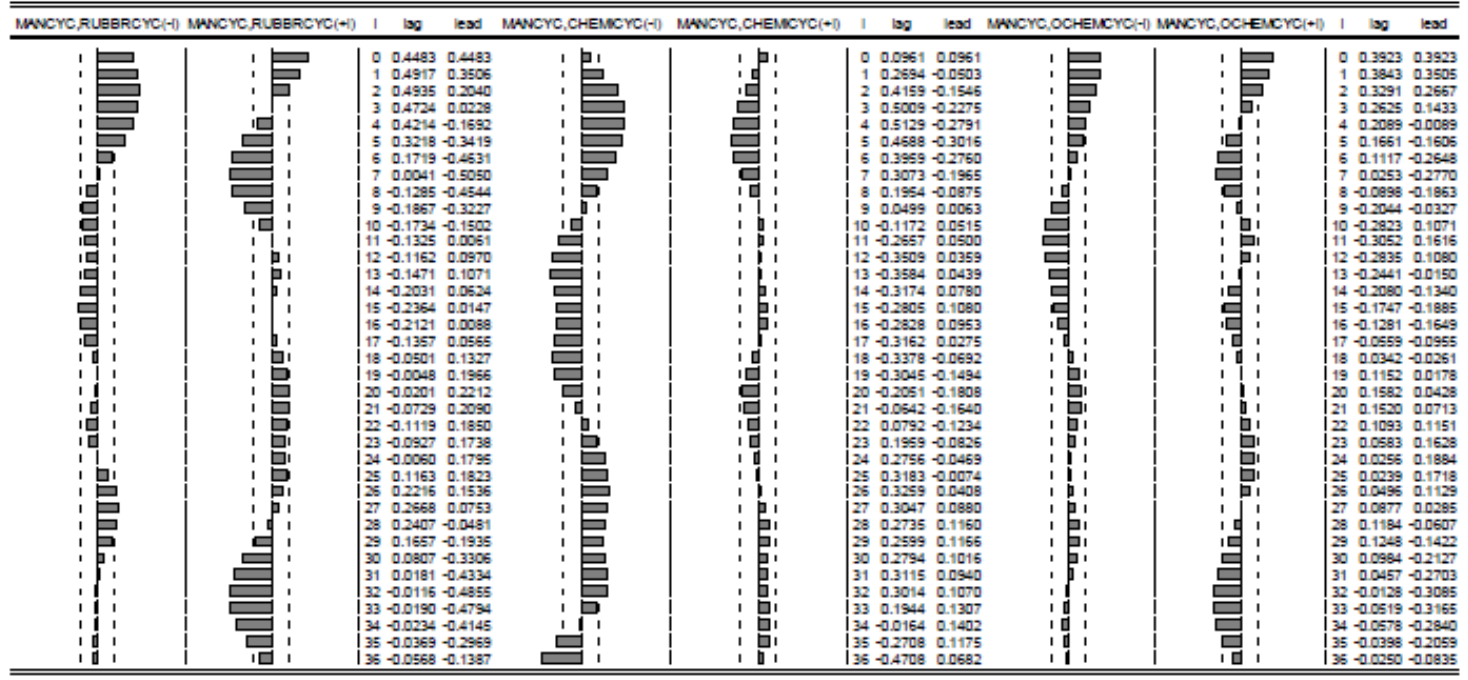

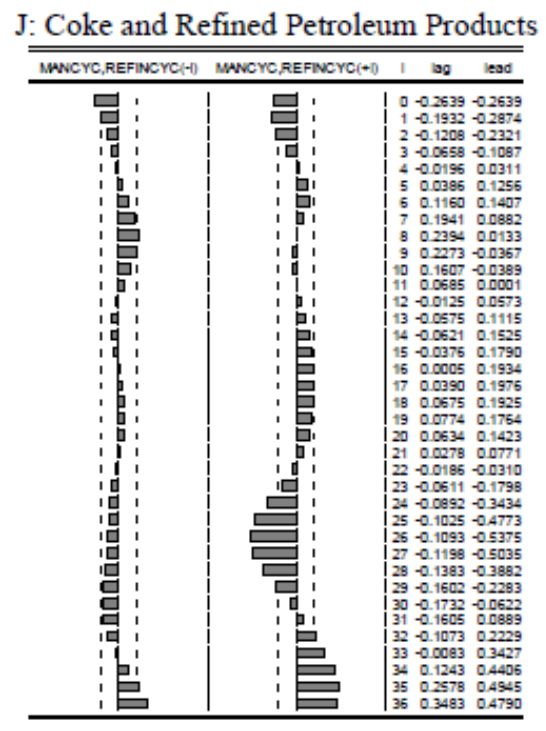

Figure 4. Cross-Correlation Functions between Common and Idiosyncratic Cycles

Table 5. Average Lag and Lead Time of Idiosyncratic Cycles Relative to Common Cycle

\begin{tabular}{|l|l|l|}
\hline Sub-Sector & Expansion (in quarters) & Contraction (in quarters) \\
\hline Food Products (FOOD) & 0.7 & -1.3 \\
\hline Basic Metals (METAL) & 1.9 & -3.0 \\
\hline Motor Vehicles, Trailers and Semi-Trailers (VEHIC) & 0.7 & -1.3 \\
\hline Textiles (TEXT) & 1.9 & -3.0 \\
\hline Fabricated metal products (FABRC) & 2.75 & 0.1 \\
\hline Wearing Apparels (WEAR) & -1.12 & -3.5 \\
\hline Rubber and Plastic Products (RUBBR) & 2.5 & 0.3 \\
\hline Chemicals and Chemical Products (CHEMI) & -0.5 & -0.5 \\
\hline Other Non-Metallic Minerals (OCHEM) & 1.5 & 2.5 \\
\hline Coke and Refined Petroleum Products (REFIN) & -1.5 & -4.5 \\
\hline
\end{tabular}


The results obtained in Figure 4 and Table 5 do not allow us to make inferences about causality. It is necessary to analyze the causality (lagging or leading) between cycles to support and reinforce the results obtained from cross-correlation functions. The traditional test method used for this purpose is the Granger-type causality test. Table 6 below summarizes the results of the Granger causality tests.

In Granger causality tests, the common cycle and sector-specific cycle series obtained in the previous sections were used. The series in question are used at their levels since they have the property of $I(0)$ due to their derivation process. In performing the relevant tests, a lag of 2 quarters determined by the Akaike and Schwarz Information Criteria (AIC and SIC) was preferred. According to the results summarized in the table, there is no causality relationship between the idiosyncratic cycles in motor vehicles, fabricated metal products, wearing apparels and the common cycle of the manufacturing industry. However, according to the table, there is one-way causality from the common cycle to textiles, other non-metallic mineral products and refined petroleum products cycles while causality runs from the chemical products cycle to the common cycle. The causality relationship between the food products, basic metals, plastic products cycles and the common cycle is bilateral. When cross-correlation analysis, average lagging - leading analysis and finally Granger causality test results are considered together, the basic metals sub-sector cycle can be used as a leading indicator of the common cycle. The idiosyncratic cycle of manufacture of basic metals signals the contraction period about 3 quarters and the expansion period about 2 quarters before.

Table 6. Granger Type Causality between Idiosyncratic and Common Cycles

\begin{tabular}{|l|l|l|l|}
\hline Relationship between Sectors & F Test & Probability & Direction of Causality \\
\hline FOOD cycle does not cause to COMMON cycle & 23.0305 & 0.0000 & FOOD $\leftrightarrow$ COMMON \\
COMMON cycle does not cause to FOOD cycle & 19.5649 & 0.0000 & \\
\hline METAL cycle does not cause to COMMON cycle & 10.2465 & 0.0001 & METAL $\leftrightarrow$ COMMON \\
COMMON cycle does not cause to METAL cycle & 14.0553 & 0.0000 & \\
\hline VEHIC cycle does not cause to COMMON cycle & 0.3990 & 0.7423 & No causality relationship \\
COMMON cycle does not cause to VEHIC cycle & 0.0264 & 0.9739 & \\
\hline TEXT cycle does not cause to COMMON cycle & 1.5846 & 0.2108 & COMMON $\rightarrow$ TEXT \\
COMMON cycle does not cause to TEXT cycle & 2.8700 & 0.0620 & \\
\hline FABRC cycle does not cause to COMMON cycle & 1.1608 & 0.3180 & No causality relationship \\
COMMON cycle does not cause to FABRC cycle & 1.4392 & 0.2426 & \\
\hline WEAR cycle does not cause to COMMON cycle & 2.0462 & 0.1353 & No causality relationship \\
COMMON cycle does not cause to WEAR cycle & 1.9664 & 0.1461 & \\
\hline RUBBR cycle does not cause to COMMON cycle & 8.8653 & 0.0003 & RUBBR $\leftrightarrow$ COMMON \\
COMMON cycle does not cause to RUBBR cycle & 7.1395 & 0.0013 & \\
\hline CHEMI cycle does not cause to COMMON cycle & 4.8477 & 0.0101 & CHEMI $\rightarrow$ COMMON \\
COMMON cycle does not cause to CHEMI cycle & 0.3568 & 0.7010 & \\
\hline OCHEM cycle does not cause to COMMON cycle & 1.2674 & 0.2866 & COMMON $\rightarrow$ OCHEM \\
COMMON cycle does not cause to OCHEM cycle & 4.4488 & 0.0144 & \\
\hline REFIN cycle does not cause to COMMON cycle & 1.9768 & 0.1446 & COMMON $\rightarrow$ REFIN \\
COMMON cycle does not cause to REFIN cycle & 2.8327 & 0.0642 & \\
\hline
\end{tabular}




\section{Conclusion}

In this study, the Butterworth filter is used to decompose the unobservable cycle and trend components of the manufacturing industry production time series in Turkey. In the analysis, 10 sub-sectors with the highest contribution representing approximately $75 \%$ of the total manufacturing industry production were included. As a result of the decomposition of the cycles, it has been determined that common (or economic) cycles are irregular and have an average duration of 4 years. The results obtained for low and high frequencies are statistically significant and close to ideal filter results since the gain functions show the expected behavior. Therefore, the decomposed trend and cycle series represent the original series appropriately.

The idiosyncratic cycles obtained for sub-sectors show that these sectors are sensitive to the common cycle. However, this relationship is weakening in sectors dependent on foreign countries in terms of production and sales, and the importance of idiosyncratic cycles increases. In most of the manufacturing industry sub-sectors examined, the variance of the idiosyncratic cycle is lower than the variance of the common cycle. This situation has shown that the possibility of using sector-specific cycles as a leading indicator of the common cycle should be investigated.

As a result of the cross-correlation analysis and Granger type causality tests, it is seen that the changes in the basic metal's production can be used as a leading indicator of the manufacturing industry common cycle. The relations determined between idiosyncratic cycles and the common cycle reveal that policies that consider the production dynamics of each sector should be given priority, especially in sectoral contractions.

\section{References}

Akkoyun, H. C., Dogan, B. S., \& Gunay, M. (2011). Turkiye Ekonomisi Is Cevrimlerinin Kuresel Ekonomi ile Iliskisi. The Central Bank of the Republic of Turkey, Economy Notes 2011/19.

Alp, H., Baskaya, Y., Kilinc, M., \& Yuksel, C. (2012). Stylized Facts for Business Cycles in Turkey. The Central Bank of the Republic of Turkey, WP2012/02.

Alper, C. (1998). Nominal stylized facts for Turkish business cycles. METU Studies in Development, 25(2), 233-244.

Alper, C. (2002). Business cycles, excess volatility and capital flows: Evidence from Mexico and Turkey. Russian and East European Finance and Trade, 38(4), 22-54.

Asik, B. (2020). Turkiye konjonkturel dalgalanmalarinin temel ozellikleri. Troyacademy, 5(1), 45-84. https://doi.org/10.31454/usb.721944

Atabek, A., Cosar, E., \& Sahinoz, S. (2005). A new composite leading indicator for Turkish economic activity. Emerging Markets Finance and Trade, 41(1), 45-64.

https://doi.org/10.1080/1540496X.2005.11052597

Baxter, M., \& King, R. (1999). Measuring business cycles: Approximate band-pass filters for economic time series. The Review of Economic Statistics, 81(4), 575-593. 
https://doi.org/10.1162/003465399558454

Berument, H., Kılınc, Z., \& Yucel, E. (2005). Business cycles in Turkey and European Union countries: A perspective to the membership. Sosyoekonomi Dergisi, 1(1), 11-26.

Binici, M., Hacihasanoglu, Y., \& Kutuk, S. (2016). Turkiye'de Finansal Cevrimler ve Is Cevrimleri: Ne Kadar Farkli, Ne Kadar Baglantili? The Central Bank of the Republic of Turkey, Economy Notes 2016-26.

Bry, G., \& Boschan, C. (1971). Cyclical Aspects of Time Series: Selected Procedures and Computer Programs. NBER Technical Papers, No: 20.

Burns, A., \& Mitchell, W. (1946). Measuring Business Cycles. NBER, Columbia University Press: New York.

Butterworth, S. (1930). On the theory of filter amplifiers. Wireless Engineer, 7(6), 536-541.

Christiano, L., \& Fitzgerald, T. (1999). The Band Pass Filter. NBER w7257: Cambridge. https://doi.org/10.3386/w7257

Emerson, R., \& Hendry, D. (1998). An evaluation of forecasting using leading indicators. Journal of Forecasting, 15, 271-291.

https://doi.org/10.1002/(SICI)1099-131X(199607)15:4<271::AID-FOR623>3.0.CO;2-7

Gomez, V. (2001). The use of Butterworth filter for trend and cycle estimation in economic time series. Journal of Business \& Economic Statistics, 19(3), 365-373.

https://doi.org/10.1198/073500101681019909

Harvey, A., \& Jaeger, A. (1993). Detrending, stylized facts and the business cycle. Journal of Applied Econometrics, 8(3), 231-247. https://doi.org/10.1002/jae.3950080302

Harvey, A., \& Trimbur, T. (2003). General models based filters for extracting cycles and trends in economic time series. The Review of Economics and Statistics, 85(2), 244-255. https://doi.org/10.1162/003465303765299774

Hodrick, R., \& Prescott, E. (1980). Post-war US Business Cycle: An Empirical Investigation. Carnegie Mellon University Discussion Paper No. 451.

Korap, L. (2007). Structural VAR Identification of the Turkish Business Cycles. MPRA Paper No. 21971.

Kydland, F., \& Zaragoza, E. (1997). Is the Business cycle of Argentina different? Federal Reserve Bank of Dallas Economic Review, 4, 21-36.

Male, R. (2011). Developing country business cycles: Characterizing the cycle. Emerging Markets Finance and Trade, 47(2), 20-39. https://doi.org/10.2753/REE1540-496X4703S202

Ozkan, I., \& Erdem, L. (2007). Turkiye ekonomisinde is cevrimlerinin tarih ve sure araliklarinin tespiti. Akdeniz Universitesi Iktisadi ve Idari Bilimler Fakultesi Dergisi, 7(14), $1-19$. 


\section{Macrothink}

Business and Economic Research ISSN 2162-4860 2021, Vol. 11, No. 2

Pagan, A. (2010). Can Turkish Recessions Be Predicted? TÜSİAD-KOÇ University Economic Research Forum Working Paper 1027.

Pelagatti, M. (2005). Business Cycle and Sector Cycles. Università degli Studi di Milano-Bicocca, Department of Statistics mimeo.

Stock, J., \& Watson, M. (1989). New indexes of coincident and leading economic indicators. NBER Macroeconomics Annual, 4, 351-409. https://doi.org/10.1086/654119

Stock, J., \& Watson, M. (1998). Business Cycle Fluctuations in US Macroeconomic Time Series. NBER w6528: Cambridge. https://doi.org/10.3386/w6528

Senyuz, Z. (2002). Time series investigation of Turkish business cycles using regime switching models. ERC/METU VI. International Conference on Economics, Ankara.

TUIK. (2019). Annual Industrial Product (Prodcom) Statistics. Turkish Statistical Institute: Ankara.

Valle, R., Gomez, H., \& Quintana, F. (2004). A new class of skew-normal distributions. Communications in Statistics: Theory and Methods, 33(7), 1465-1480.

https://doi.org/10.1081/STA-120037254

Note

Note 1. "If the number of enterprise in any cell of the data table is less than three, the data are not given by law No 5429. Pertaining to enterprise of hidden data are not given for hinder to obtain confidential figures by mathematical process. If the number of enterprise in any cell of the data table is less than three or one or two of enterprises are dominant even if the enterprise is three or more, the data are not given by law No 5429. Hidden sector data are shown in sum of two or three-digit level sector codes and national total (TUIK, 2019)".

Note 2. An ideal filter should be symmetrical, not create phase changes, produce stationary series, and not change other frequency characteristics other than the applied one. For detailed information on ideal filters, see Harvey \& Trimbur (2003). 
Appendix

Appendix: Manufacturing Industry Production Indices (1997=100 and 2015=100)

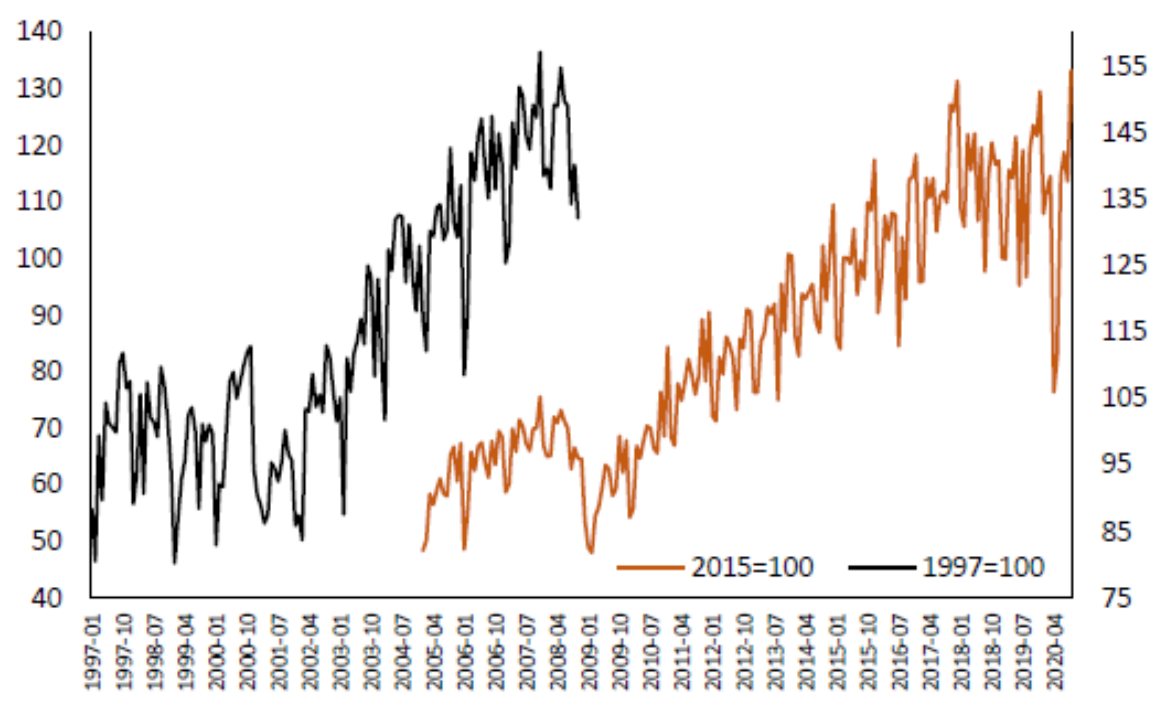

\section{Copyright Disclaimer}

Copyright for this article is retained by the author(s), with first publication rights granted to the journal.

This is an open-access article distributed under the terms and conditions of the Creative Commons Attribution license (http://creativecommons.org/licenses/by/4.0/). 